\title{
PANJI SAKTI “THE KING OF BULELENG” : GAME 3D CERITA RAKYAT BERBASIS DESKTOP
}

\author{
Putu Gilang Pratama1, Gede Saindra Santyadiputra², Made Windu Antara \\ Kesiman $^{3}$ \\ 1,2,3 Prodi Pendidikan Teknik Informatika Jurusan Tektik Informatika Fakultas Teknik dan Kejuruan Universitas \\ Pendidikan Ganesha, JIn. Udayana No.11 Singaraja 81116 INDONESIA
}

\begin{abstract}
Abstrak
Game 3D cerita rakyat berbasis desktop ini menceritakan tentang riwayat hidup dari Panji Sakti atau sering dikenal juga sebagai Ki Barak Panji Sakti yang merupakan raja pertama Buleleng. Akan tetapi masih banyak masyarakat yang tidak mengetahui tentang cerita rakyat Panji Sakti. Terbukti dari angket yang disebar peneliti. Selain itu media untuk menceritakan cerita rakyat Panji Sakti masih dalam bentuk buku, dimana ini merupakan bentuk kuno di zaman yang sudah modern. Yang mengakibatkan kurangnya minat untuk mengetahui cerita Panji Sakti itu sendiri. Tujuan dari penelitian ini adalah untuk mengimplementasikan rancangan game 3D cerita rakyat Panji Sakti yang nantinya dapat menambah minat masyarakat untuk melestarikan cerita rakyat Panji Sakti. Game 3D cerita rakyat ini menggunakan metode Game Development Life Cycle. Hasil akhir dari game ini berupa program executable.
\end{abstract}

Kata Kunci:

Cerita Rakyat Panji Sakti, Game, Pemodelan

3 Dimensi

\begin{abstract}
This desktop-based 3D folklore game tells about the life history of Panji Sakti or often known as Ki Barak Panji Sakti who was the first king of Buleleng. However, there are still many people who do not know about the folklore of Panji Sakti. Evidenced by a questionnaire distributed by researchers. In addition, the media for telling the Panji Sakti folklore is still in book form, which is an ancient form in modern times. Which resulted in a lack of interest in knowing the Panji Sakti story itself. The purpose of this research is to implement the 3D folklore game design of Panji Sakti which later can increase public interest in preserving the folklore of Panji Sakti. This 3D folklore game uses the Game Development Life Cycle method. The final result of this game is an executable program.
\end{abstract}

\author{
Keywords: \\ Folklore of Panji Sakti, \\ Game, 3D Modelling
}

\section{PENDAHULUAN}

Indonesia merupakan negara yang memiliki beragam aneka budaya dan seni. Salah satunya yaitu cerita rakyat yang setiap daerahnya memiliki cerita rakyatnya masing-masing. Cerita rakyat merupakan cerita yang bersumber dari masyarakat dan berkembang dalam masyarakat di masa lampau yang menjadi ciri khas dari bangsa dan daerahnya yang memiliki kultur budaya yang beragam mencakup kekayaan budaya dan sejarah yang dimiliki bangsa dan daerah itu sendiri (Fathoni, 2018). Cerita rakyat biasanya menceritakan suatu kejadian atau asal usul suatu tempat. Tokoh didalam cerita rakyat umumnya dalam bentuk binatang, manusia, jin maupun yang lainnya. Cerita rakyat haruslah dilestarikan karena merupakan warisan dan budaya dari daerah dan bangsanya. Namun pada zaman modern ini, generasi sekarang kurang tertarik melestarikan cerita rakyat di derahnya. Disamping itu cerita rakyat sebagian besar diperkenalkan melalui media buku. Hal itu dianggap sebagai hal kuno di zaman sekarang yang mengakibatkan kurangnya pelestarian cerita rakyat itu sendiri. Di Bali ada banyak dan beragam cerita rakyat yang sudah diceritakan turun-temurun oleh masyarakat. Kabupaten Buleleng khususnya ada cerita rakyat yang menceritakan tentang kisah Panji Sakti raja Buleleng pertama. Akan tetapi menurut survei yang dilakukan Darma (2017), pemuda dengan rentan usia 16-30 tahun hanya 55,2\% yang menjawab pernah mendengar cerita rakyat

\footnotetext{
* Korespondensi

E-mail: gilangprtm210498@gmail.com¹,gsaindras@undiksha.ac.id², antara.kesiman@undiksha.ac.id ${ }^{3}$
} 
Panji Sakti. Sedangkan menurut survei yang peneliti lakukan, mendapatkan hasil bahwa hanya 41,6\% masyarakat yang mengetahui cerita rakyat Panji Sakti dan 58,3\% yang tidak mengetahui cerita rakyat Panji Sakti. Perlu bentuk lain untuk menyajikan sebuah cerita rakyat agar menjadi lebih menarik di zaman modern ini, salah satunya itu game. Game saat ini sedang populer di masyarakat, karena dapat menghibur dan sangat menarik untuk dimainkan. Tidak hanya sekedar menjadi sarana hiburan, game juga dapat menjadi sarana untuk menyampaikan sebuah informasi ataupun cerita, serta dapat menjadi sarana edukasi untuk melatih daya pikir. Terdapat beberapa genre game, diantaranya yaitu action, adventure game, role playing game dan masih banyak lagi. Game yang bertemakan cerita rakyat sudah berkembang di Indonesia, contohnya pengembangan game yang berjudul Rancang Bangun Aplikasi Pengenalan Cerita Rakyat Timun Mas Berbasis Game 3D. Dengan hasil Game ini cukup membuat para respoden penasaran kemudian tertarik untuk mencoba. karena mereka merasa game 3D yang mengangkat cerita adat sebagai alur cerita masih relatif jarang (Fathoni, 2018). Contoh lainnya yaitu dari Tjahjono (2015) dengan judul Pembuatan Game Cerita Rakyat Dengan Bentuk Adventure Game. Maka itu penulis ingin melestarikan cerita rakyat khususnya di Buleleng. Dengan cara menggabungkan game dan unsur cerita rakyat didalamnya. Penulis bermaksud untuk merancang sebuah game yang bertemakan cerita rakyat Panji Sakti. Game ini akan dikembangkan dengan model 3D. Teknologi 3D dapat menghadirkan tampilan yang lebih nyata dibandingkan dengan model 2D. Dalam pengembangannya Unreal Engine 4 akan digunakan sebagai aplikasi utama dalam pengembangan game ini. Dengan harapan game ini akan menarik perhatian generasi sekarang dan mau melestarikan cerita rakyat yang mulai dilupakan. Berdasarkan hal yang sudah di uraian diatas, penulis melakukan penelitian ini dengan judul "Panji Sakti "The King of Buleleng”: Game 3D Cerita Rakyat Berbasis Desktop".

\section{METODE}

Dalam pengembangan game Panji Sakti ini menggunakan metode Game Development Life Cycle (GDLC). GDLC adalah sebuah metode pembangunan dan pengembangan game, dimana di dalamnya ada tahapan inititation (inisiasi), pre-production (pre-produksi), production (produksi), testing (uji coba), beta, release (rilis).

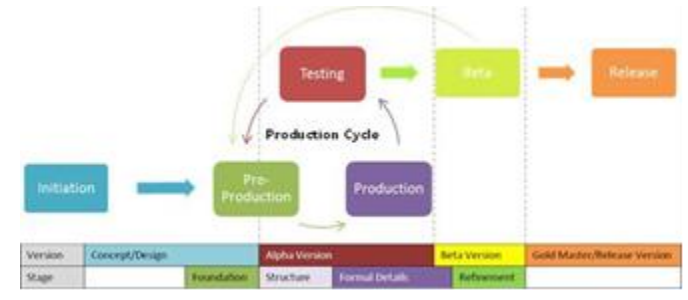

Gambar 1. Tahapan dalam metode Game Development Life Cycle (GDLC)

(Sumber: researchgate.net)

1. Inisiasi

Inisiasi yaitu perumusan ide awal game. Pada tahapan ini akan ditentukan pola dan cara bermain (konsep) pada game yang akan dibangun. Konsep dari game ini pemain akan mengendalikan karakter utama yaitu Panji Sakti yang akan melakukan perjalanan serta menghadapi rintangan dan musuh di dalam game. Game ini bergenre action-adventure. Menggunakan teknologi 3D dengan harapan dapat menampilkan dan menyampaikan cerita rakyat Panji Sakti lebih menarik. Dalam pengembangannya menggunakan aplikasi 3D modelling yaitu blender untuk membuat karakter dan objek 3D. Unreal Engine 4 digunakan untuk mengolah semua yang diperlukan untuk membuat game, dimana pengkodean dilakukan sepenuhnya di aplikasi ini. Game ini dimainkan pada perangkat komputer. Menggunakan mouse dan keyboard sebagai alat input dalam game. Akan ada beberapa stage yang disetiap stagenya akan menyajikan petualangan serta pengalaman bermain yang berbeda. Hal ini yang akan menjadi tantangan tersendiri bagi pemain.

2. Pre-Produksi

Pada tahap Pre-produksi, berdasarkan hasil penentuan konsep pada tahapan inisiasi, pada tahapan ini akan dibuat desain karakter, desain latar, desain objek, dan piranti lunak apa saja yang diperlukan untuk membangun game tersebut.

3. Produksi

Pada tahapan ini akan dilakukan pengkodean, perancangan alur aplikasi dan proses penggabungan semua unsur game seperti model karakter, asset 3D, sound effect yang digunakan sehingga game dapat dijalankan sebagaimana mestinya. 
4. Uji coba

Pada tahapan ini dilakukan uji coba internal menggunakan uji coba bermain untuk menilai fungsi game dan keseimbangan game. Hasil dari uji coba ini adalah pelaporan bug, pengubahan permintaan, dan keputusan pembangunan game. Dilakukan 2 pengujian yaitu, pengujian blackbox, dan pengujian ahli media.

5. Beta

Pada tahapan beta membutuhkan tester eksternal. Dari sini, jika diperlukan perubahan pada fitur atau gameplay, maka siklus GDLC dapat berulang. Dilakukanlah uji pengguna.

6. Rilis

Tahapan ini merupakan tahapan penyelesaian game yang sudah selesai dibangun dan siap dirilis. Dan game akan berbentuk executable.

\section{HASIL DAN PEMBAHASAN}

Hasil yang didapatkan dari game Panji Sakti berdasarkan metode Game Development Life Cycle. Peneliti melakukan pengujian pada game yang dibuat, seperti pengujian blackbox, penguijan ahli media, dan pengujian pengguna. Pemaparan mengenai hasil dari penelitian dan pengujian akan dielaskan sesuai dengan metode Game Development Life Cycle pada berikut ini.

\section{A. Inisiasi}

Inisiasi yaitu perumusan ide awal game. Pada tahapan ini akan ditentukan pola dan cara bermain (konsep) pada game yang akan dibangun. Pada tahapan ini peneliti mengimplementasikan konsep yang sudah direncanakan sebelumnya kedalam Unreal Engine, seperti konsep karakteristik dari masing-masing stage beserta halangan dan rintangannya.

Rincian stage yang sudah diimplementasikan adalah sebagai berikut:

1) Stage pertama yang berlatar daerah gelgel dimana Panji Sakti memulai perjalanannya. Pada stage ini pemain harus memenuhi objective yaitu membunuh beberapa musuh, setelah objective terselesaikan akan muncul portal untuk melanjutkan ke stage berikutnya. Terdapat juga halangan berupa batu besar mengahalangi jalan yang harus dilewati untuk sampai ketempat portal berada.

2) Tahap kedua Panji Sakti sedang menyusuri hutan, didalam perjalanannya dihutan akan ada jebakan seperti jalan buntu berjurang dimana pemain akan mencari cara agar bisa dilewati dan rintangan yang dihadapi serta musuh yang harus dibunuh untuk menyelesaikan objective.

3) Tahap ketiga Panji Sakti sampai di desa Panji, dimana dia akan melawan sosok Ki Gendis dan menjadi raja daerah Panji. Sebelum melawan Ki Gendis, pemain akan membantu warga yang diganggu oleh bawahan Ki Gendis. Pada tahap ini pemain akan melawan banyak musuh karena sudah memasuki daerah kekuasaan Ki Gendis.

4) Tahap keempat Panji Sakti menolong kapal yang terdampar, dimana dia akan melawan banyak perompak yang menguasai kapal. Dan membebaskan kapal dari para perompak yang menguasai kapal.

5) Tahap kelima Panji Sakti memindahkan kerajaannya ke daerah yang dipenuhi tumbuhan Buleleng, diberi namalah daerah tersebut Buleleng dengan istananya di Singaraja. Dalam pemindahannya, pemain akan mengumpulkan item di berbagai tempat, akan ada rintangan dan musuh yang menghadang di setiap item. Jika sudah terkumpul dan dibentuk Kerajaan Buleleng. Akan ada narasi terakhir dan menandakan game sudah terselesaikan sepenuhnya.

\section{B. Pre-produksi}

Pada tahap Pre-produksi, berdasarkan hasil penentuan konsep pada tahapan inisiasi, pada tahapan ini akan dibuat desain karakter, desain latar, desain objek, dan piranti lunak apa saja yang diperlukan untuk membangun game tersebut.

\section{a. Kebutuhan Fungsional}

Kebutuhan fungsional merupakan kebutuhan akan fasilitas yang tersedia serta aktivitas apa saja yang dilakukan oleh sistem secara umum. Hasil dari kebutuhan tersebut adalah sebagai berikut:

1. Dalam layar awal game Panji Sakti ini pemain akan dapat memilih beberapa menu utama, yaitu Play Game, Continue, Setting, dan Exit Game. 


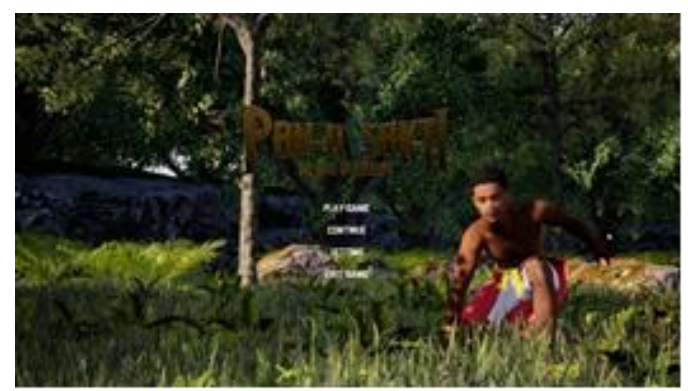

Gambar 2. Menu Utama

2. Dalam game akan ada narasi yang bersubtitle Bahasa Inggris untuk membantu pemain dan menjelaskan kejadian yang sedang terjadi. Dengan begitu pemain akan paham tentang alur cerita rakyat Panji Sakti. Berbahasa Inggris juga merupakan bahwa game ini menargetkan pasar luar negeri.

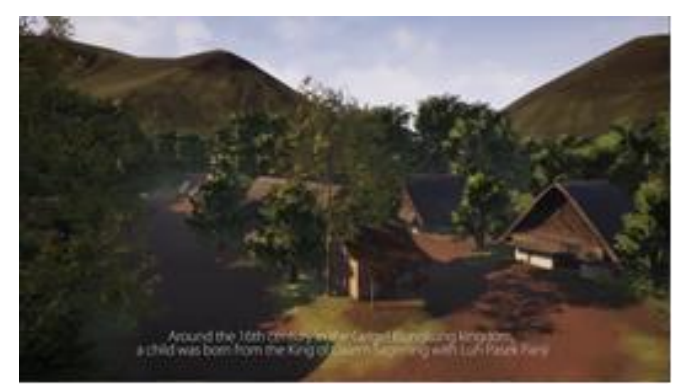

Gambar 3. Subtitle dalam Game

3. Memiliki beberapa stage untuk diselesaikan dengan berbagai halangan, jika halangan sudah terlewati maka akan muncul portal stage yang berfungsi untuk melanjutkan ke stage selanjutnya.

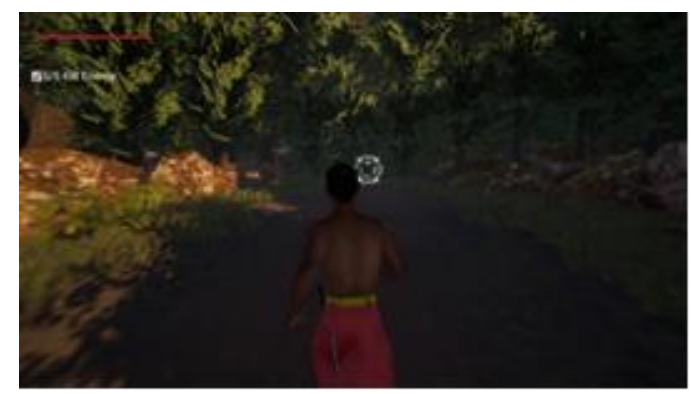

Gambar 4. Portal Stage

4. Tombol Esc akan berfungsi sebagai pause menu dan menampilkan menu, yaitu Resume, Save, Main Menu, dan Exit Game.

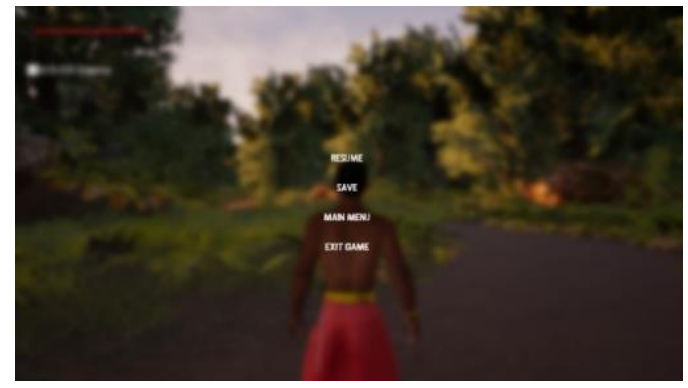

Gambar 5. Pause Menu 
5. Menampilkan menu game over ketika pemain mengalami kekalahan. Menampilkan pilihan Restart Stage, Main Menu dan Exit Game.

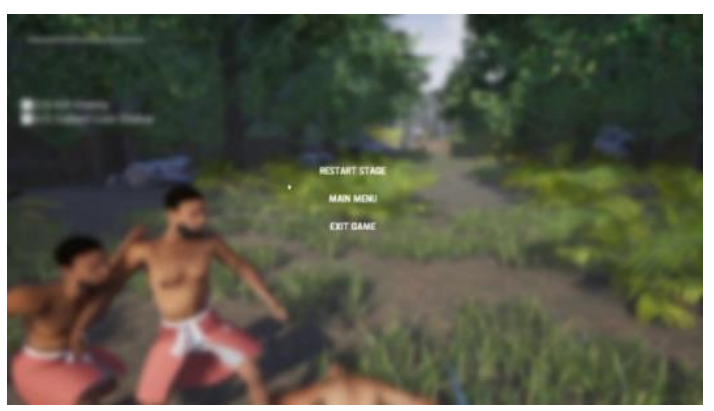

Gambar 6. Game Over Menu

\section{b. Kebutuhan Non Fungsional}

Kebutuhan non fungsional merupakan kebutuhan untuk memenuhi kebutuhan fungsional yang sudah disampaikan. Berikut kebutuhan fungsional game Panji Sakti ini:

1. Perangkat Keras

Agar aplikasi dapat berjalan dengan baik, maka dibutuhkan perangkat keras yang sesuai dengan kebutuhan aplikasi. Adapun perangkat keras yang digunakan untuk mengembangkan game ini, yaitu:

1). Komputer, spesifikasi komputer yang digunakan:
a. Processor AMD Ryzen R5 3600
b. RAM 16 GB
c. VGA MSI $16504 \mathrm{~GB}$
d. HDD Sata $1 \mathrm{~TB}$
e. Sistem operasi Windows 10

2. Perangkat Lunak

Adapun beberapa perangkat lunak yang digunakan untuk mengembangkan game ini, yaitu:

1). Blender 3D 2.79

2). Unreal Engine 4

3. Sumber Daya Manusia

Kebutuhan ini meliputi individu yang akan terlibat langsung dalam pembuatan game edukasi ini. Manusia sebagai pencipta dan pengguna sistem sehingga sistem ini bisa digunakan sesuai fungsinya.

\section{c. Hasil dari rancangan karakter}

Tabel 1. Hasil Karakter

\begin{tabular}{l}
\hline No Karakter \\
\hline 1 \\
23
\end{tabular}




\section{d. Hasil dari rancangan stage}

Tabel 2. Hasil Stage

No
$\begin{aligned} & \text { Akan menampilkan keadaan wilayah gelgel dengan latar desa, } \\ & \text { dan menampilkan hutan setelah keluar dari desa. }\end{aligned}$
3
4

\section{e. Hasil dari rancangan interface}

Tabel 3. Hasil Interface

\begin{tabular}{lll}
\hline No & Keterangan \\
\hline 1 & $\begin{array}{l}\text { Interface menu utama (main menu). } \\
\text { Terdapat pilihan yaitu play game, continue, } \\
\text { setting, dan exit game }\end{array}$ \\
3 & $\begin{array}{l}\text { interface pause menu. Terdapat beberapa } \\
\text { pilihan yaitu resume, save, main menu, dan } \\
\text { exit game. }\end{array}$ \\
& $\begin{array}{l}\text { Interface } \\
\text { beberapa pilihan yaitu restart stage, main } \\
\text { menu dan exit game. }\end{array}$ \\
\end{tabular}

\section{Produksi}

Pada tahapan ini akan dilakukan pengkodean, perancangan alur aplikasi dan proses penggabungan semua unsur game seperti model karakter, asset 3d, sound effect yang digunakan sehingga game dapat dijalankan sebagaimana mestinya. 
1) Pembuatan model $3 \mathrm{~d}$

Pada pembuatan model 3d ini dibagi menjadi 2 bagian. Yaitu pada bagian aplikasi blender 2.79 untuk pembuatan model karakter dan asset dan di unreal engine untuk pembuatan level stage atau tempat terjadinya game. Proses pembuatan karakter dimulai dari modelling di aplikasi blender. Di buat menyesuaikan desain karakter yang sudah ditetapkan sebelumnya. Karakter yang dibuat yaitu panji sakti, ki gendis, ibu panji, dan musuh. Proses pembuatan level stage dilakukan didalam unreal engine. Pada pembuatannya mengikuti desain pada rancangan yang sudah ditentukan sebelumnya. Hal pertama yang harus dilakukan yaitu penyesuaian terrain atau dataran yang digunakan berpijak pada game. Untuk menyesuaikan terrain, kita menggunakan tools yang ada pada landscape editor. Dimana kita bisa mengatur tinggi rendahnya permukaan yang nantinya digunakan untuk pijakan pada game. Setelah pengaturan terrain, hal selanjutnya yaitu penyesuaian environment atau lingkungan, seperti penambahan pepohonan atau object lainnya. Untuk penambahannya kita tinggal drag and drop asset mana yang akan digunakan dan ditempatkan di posisi yang diinginkan.

2) Membuat Program

Proses membuat program atau pengkodean dilakukan di aplikasi Unreal Engine. Pengkodean dilakukan untuk membuat mekanik gameplay sesuai dengan rancangan yang sudah dibuat sebelumnya. Pengkodean di Unreal Engine menggunakan blueprint script dimana kita memanggil fungsi yang sudah disediakan dan menyelaraskannya dengan fungsi yang lain.

a. Input Setting Karakter Panji

Karakter Panji memiliki beberapa script yang berfungsi untuk mengatur gameplay. Tapi sebelum melakukan pengkodean, kita harus menyesuaikan input yang diberikan contohnya seperti input klik kiri pada mouse berfungsi untuk menyerang. Pengaturan input ini bisa diatur pada project setting.

b. Script Berjalan

Script ini berfungsi untuk karakter dapat melakukan gerakan berjalan dengan menggunakan input WASD pada keyboard.

c. Script Berlari dan Jongkok

Script ini berfungsi agar karakter dapat berlari dengan kecepatan yg ditentukan dan melakukan gerakan jongkok

d. Script Mendorong

Script ini berfungsi untuk mendorong suatu object, didalam game object yang bisa didorong berupa batu pada stage 1 . Fungsi mendorong ini menggunakan tombol E pada keyboard.

e. Script Memanjat

Script ini berfungsi untuk memanjat suatu object. Fungsi memanjat menggunakan tombol F pada keyboard

f. Script Mengeluarkan Senjata

Script ini berfungsi untuk mengambil senjata dengan tombol Q pada keyboard.

g. Script Melakukan Serangan

Script ini berfungsi agar karakter dapat melakukan serangan. Tombol yang digunakan yaitu klik kiri pada mouse. Karakter dapat melakukan 3 jenis serangan dan dapat disesuaikan dengan animasi yang sudah didownload sebelumnya pada mixamo.

h. Script Menerima Damage Serangan

Script ini berfungi untuk karakter ketika menerima serangan maka jumlah health atau darah akan berkurang, dan ketika mencapai 0 maka karakter akan mati dan muncul Death Menu pada layar.

i. Script AI Bergerak Mendekati Pemain

Script ini ditunjukan untuk AI atau musuh didalam game untuk dapat bergerak mendekati pemain dengan radius yang sudah ditentukan. AI mendeteksi pemain menggunakan AI pawnsensing.

j. Script AI Menyerang

Script ini berfungsi untuk AI dapat menyerang pemain pada jarak tertentu. Pada script ini AI dapat melakukan 3 jenis gerakan serangan yang berbeda. Jenis dan jumlah gerakan dapat diatur sesuai kebutuhan.

k. Script AI Terkena Damage dan Mati

Script ini berfungsi agar AI dapat terkena serangan serta menurunkan jumlah health yang dimiliki. Apabila health sudah mencapai 0 maka AI akan mati dan menghilang.

1. Membuat Tampilan Menu

Untuk dapat membuat tampilan menu, baik Main Menu, Pause Menu maupun Death Menu. Hal yang harus dilakukan pertama kali adalah membuat widget blueprint. Didalam widget blueprintlah kita akan menyesuaikan isinya tergantung ingin membuat bagian menu yang mana. Setelah itu berikan tombol tombol yang berfungsi sesuai rancangan yang sudah dibuat sebelumnya. 
m. Menampilkan Animasi Cerita pada Game

Animasi cerita ini bertujuan agar pengguna dapat mengetahui inti informasi pada game yang dimainkan, dalam kasus ini cerita rakyat panji sakti sendiri. Hal pertama yang dilakukan yaitu menyesuaikan latar animasi dan kegiatannya serta merekamnya. Setelah melakukan perekaman, export agar menjadi video berekstensi .mp4 dan import ke dalam Unreal Engine. Langkah selanjutnya yaitu membuat widget blueprint, agar video dapat tampil dilayar pengguna.

n. Packaging Game

Membuat execute aplication yang dapat langsung dimainkan.

\section{Uji coba}

Pada tahapan ini dilakukan uji coba internal menggunakan uji coba bermain untuk menilai fungsi game dan keseimbangan game. Hasil dari uji coba ini adalah pelaporan bug, pengubahan permintaan, dan keputusan pembangunan game.

1. Hasil pengujian blackbox

Pengujian blackbox mencoba semua fungsi dengan memakai perangkat lunak apakah sesuai dengan fungsi yang dibutuhkan. Pengujian ini dilakukan secara internal. Hasil pengujiannya menunjukan semua fungsi didalam game Panji Sakti “The King Of Buleleng” berjalan sukses dan sesuai dengan fungsinya.

2. Hasil pengujian ahli media

Uji ahli media digunakan sebagai acuan untuk mengetahui kesesuaian secara teknis. Uji ahli media menggunakan angket dengan melibatkan 2 ahli media. Dengan merumuskan 8 butir soal didapatkan perhitungan sebagai berikut.

Dengan $\mathrm{K}$ merupakan presentase, $\mathrm{F}$ total penilaian dari ahli media, $\mathrm{R}$ jumlah ahli media, $\mathrm{N}$ nilai terbesar, I jumlah soal.

$$
\begin{aligned}
K & =\frac{F}{N \times I \times R} \times 100 \% \\
K & =\frac{16}{1 \times 8 \times 2} \times 100 \% \\
K & =100 \%
\end{aligned}
$$

Dilihat dari hasil uji ahli yang berasal dari dosen prodi Pendidikan Teknik Informatika yaitu, I Nengah Eka Mertayasa, S.Pd., M.Pd. Dan I Gede Partha Sindu, S.Pd., M.Pd. Hasilnya Game Panji Sakti "The King Of Buleleng" ini mendapatkan presentase rata-rata kelayakan 100\%, sehingga dapat dikategorikan Sangat Layak.

\section{E. Beta}

Pada tahapan beta membutuhkan tester eksternal atau respon pengguna. Uji respon pengguna dilakukan untuk mengetahui kepuasan pemain setelah memainkan game. Dengan menanyakan 15 butir soal kepada 30 responden, didapatkan hasil perhitungan sebagai berikut:

$$
\begin{aligned}
\text { Score total } & =1889 \\
\text { Butir soal } & =15 \\
\text { Score maksimum } & =\text { butir soal } \times \text { responden } \times \text { score tertinggi } \\
& =15 \times 30 \times 5 \\
& =2250 \\
\text { Presentase } & =\frac{\text { Total Score }}{\text { Score Maksimum }} \times 100 \% \\
& =\frac{1889}{2250} \times 100 \% \\
& =83,9 \%
\end{aligned}
$$

\begin{tabular}{|c|c|c|c|}
\hline Engine & 9/25/2020 9:16 PM & File folder & \\
\hline MyProject1 & 9/25/2020 9:16 PM & File folder & \\
\hline 娄 Manifest_NonUFSFiles_Win64 & 9/25/2020 9:16 PM & Text Document & $3 \mathrm{~KB}$ \\
\hline (11) PanjiSakti & 9/25/2020 9:14 PM & Application & $183 \mathrm{~KB}$ \\
\hline
\end{tabular}

Berdasarkan perhitungan presentase dalam skala likert, game Panji Sakti "The King Of Buleleng" mendapatkan presentase 83,9\% dimana nilai tersebut berada dalam kategori Sangat Layak.

\section{F. $\quad$ Rilis}

Pada tahapan ini game Panji Sakti "The King Of Buleleng" sudah dalam bentuk aplikasi dan bisa langsung dimainkan.

Gambar 7. Aplikasi Game Panji Sakti 


\section{SIMPULAN DAN SARAN}

Berdasarkan hasil penelitian dan pembahasan dapat disimpulkan sebagai berikut:

1. Pengembangan game Panji Sakti "The King of Buleleng" dilakukan dengan beberapa tahapan yaitu inisiasi, pre-produksi, produksi, testing, beta, dan release. Game Panji Sakti "The King of Buleleng" dikembangkan dengan software Unreal Engine 4.

2. Hasil pengujian game Panji Sakti "The King of Buleleng" meliputi pengujian blackbox, pengujian ahli media, dan pengujian terhadap pengguna dengan hasil sebagai berikut: a) pengujian blackbox mendapatkan hasil game sudah dapat berfungsi dengan baik sebagaimana yang direncanakan, b) pengujian ahli media dikategorikan sangat layak dengan hasil presentase $100 \%$, c) pengujian terhadap pengguna dikategorikan sangat layak dengan hasil presentase 83,9\%.

Sangat disadari game Panji Sakti “The King of Buleleng” ini jauh dari kata sempurna dan masih terdapat kekurangan. Dalam game Panji Sakti "The King of Buleleng" ini masih bisa diperbaiki ataupun dikembangkan, sehingga terdapat beberapa saran untuk pengembangan ke depannya agar lebih baik yaitu:

1. Model 3D dari karakter yang digunakan bisa lebih didetail lagi.

2. Bisa ditambahkan beberapa halangan serta objective agar menambah pengalaman dalam game.

3. Menambahkan mekanisme atau puzzle didalam game agar menambah variasi gameplay dalam game dan game tidak membosankan.

\section{Ucapan Terima Kasih}

Dalam penyusunan penulis banyak mendapat bantuan dari berbagai pihak, baik itu bantuan moral maupun spiritual. Maka dari itu pada kesempatan ini penulis ingin menyampaikan rasa terimakasih kepada: Gede Saindra Santyadiputra, S.T., M.Cs. selaku Pembimbing I dan Made Windu Antara Kesiman, S.T., M.Sc., Ph.D. selaku Pembimbing II yang telah banyak memberikan bimbingan, arahan, saran dan motivasi dalam proses penelitian yang penulis lakukan. Seluruh staf dosen dan pegawai Fakultas Teknik dan Kejuruan yang telah banyak membantu kelancaran pelaksanaan penelitian ini. Kedua orang tua tercinta penulis yang selalu memberikan kasih sayang, semangat, inspirasi dan tentunya dukungan materi dan non materi sehingga penulis bisa menyelesaikan penelitian ini. Rekan - rekan mahasiswa Program Studi Pendidikan Teknik Informatika yang telah banyak memberikan dukungan dan bantuan serta semua pihak yang tidak dapat penulis sebutkan satu persatu yang telah membantu penyelesaian penelitian ini

\section{Daftar Pustaka}

Adiwikarta, R., Dirgantara, H. B. (2017). Pengembangan Permainan Video Endless Running Berbasis Android Menggunakan Framework Game Development Life Cycle. Kalbiscentia Jurnal Sains dan Teknologi. 4(2), 142-148. Tersedia: (http://research.kalbis.ac.id/Research/Files/Article/Full/878IVF1Q2PRZ7GIWSF2KINATI.pdf. Diakses 10 Desember 2019)

Afif, R. L., Satoto, K. I., Martono, K. T. (2014). Perancangan PC Game First Person Shooter Menggunakan Unreal Development Kit. Jurnal Teknologi dan Sistem Komputer. 2(2), 149-156. Tersedia: (https://jtsiskom.undip.ac.id/index.php/jtsiskom/article/view/5483/5272. Diakses 10 Desember 2019)

Fathoni, K., Nur Hasim, J. A., Fathony, M. Z., Hakkun, R. Y., Asmara, R. (2018). Rancang Bangun Aplikasi Pengenalan Cerita Rakyat Timun Mas Berbasis Game 3D. Jurnal Nasional Teknologi Terapan. 2(1), 6270. Tersedia: (https://jurnal.ugm.ac.id/jntt/article/view/39160/22371. Diakses 11 Desember 2019)

Darma, N. T. A, Arthana, I K. R., Putrama, I M. (2017). Pengembangan Aplikasi Game Kisah Panji Sakti Berbasis Mobile. Jurnal Nasional Pendidikan Teknik Informatika. 6(3), 283-294. Tersedia: (https://ejournal.undiksha.ac.id/index.php/janapati/article/view/12018/pdf. Diakses 11 Desember 2019)

International Design School. (2016, November 25). Memahami Lebih Dalam Pengertian Animasi 3D. Tersedia: (https://idseducation.com/articles/memahami-lebih-dalampengertian-animasi-3d/)

Prayudi, K. A. W., Arthana, I. K. R., \& Wirawan, I. M. A. (2015). Pengembangan Game Labrin Matematika Tingkat SD. Kumpulan Artikel Mahasiswa Pendidikan Teknik Informatika, 4(5), 414-421.

Wati, M. S., Darmawiguna, I. G. M., \& Putrama, I. M. (2016). Pengembangan Game “Meboros Kidang” Sebagai Bentuk Pelestarian Tradisi Meboros di Bali. Kumpulan Artikel Mahasiswa Pendidikan Teknik Inforrmatika (KARMAPATI), Volume 5(Nomor 1), 20-27. Retrieved from 
https://ejournal.undiksha.ac.id/index.php/KP/article/view/6797

Indra, D., Darmawiguna, I. G. M., \& Arthana, I. K. R. (2015). "Escape from Ancient Bali" Game Adventure Berbasis Edukasi dan Budaya. Kumpulan Artikel Mahasiswa Pendidikan Teknik Informatika (KARMAPATI), Volume 4(Nomor 5), 422-429.

Renavitasari, I. R. D., Irawati, D. A., \& Prasetyo, A. (2016). Pengembangan Game Edukasi Pengenalan Budaya Indonesia "Jelajah" Berbasis Android. Seminar Informatika Aplikatif Polinema 2016, Volume 1, 1-5.

F. A. Purnomo, E. H. Pratisto, T. NH, F. Sahrul, and I. P. Lestari, "Pembuatan Game Edukasi 'Petualangan Si Gemul' Sebagai Pembelajaran Pengenalan Daerah Solo Raya Pada Anak," J. Simetris, vol. 7, no. 2, pp. 619-626, 2016.

J. B. Cakra, "Pembuatan Game Bergenre Side Scroller 2.5D Bertemakan Cerita Rakyat Sawunggaling Berjudul 'The Legend of Sawunggaling,"' Institut Bisnis dan Informatika STIKOM Surabaya, 2018.

M, Septya., dkk.2016. Game Sejarah Terbentuknya Kota Samarinda Menggunakan Role Playing Game (RPG) Maker VX Ace. Jurnal Infotel 8(1) 56-63. Tersedia Pada https://media.neliti.com/media/publications/103942-ID-game-sejarah-terbentuknya-kotasamarinda.pdf.

Slick, J. (2018, Maret 25). What Is 3D Modeling?. Tersedia: (https://www.lifewire.com/what-is-3dmodeling-2164)

Justin P. (2016). 3D Game Design with Unreal Engine 4 and Blender. Packt Publishing 2016

Satheesh PV. (2016). Unreal Engine 4 Game Development Essentials. Packt Publishing 2016.

Alireza Tavakkoli. (2018). Game Development and Simulation with Unreal Technology, second edition. CRC Press 2018. 